\title{
Geometric Morphometrics for the Study of Hemicoxae Sexual Dimorphism in a Local Domestic Equine Breed
}

\author{
Morfometría Geométrica para el Estudio del Dimorfismo \\ Sexual Hemicoxae en una Raza Equina Doméstica Local
}

Pere M. Parés-Casanova \& Sara Martínez

PARÉS-CASANOVA, P. M. \& MARTÍNEZ, S. Geometric morphometrics for the study of hemicoxae sexual dimorphism in a local domestic equine breed. Int. J. Morphol., 31(2):623-628, 2013.

SUMMARY: Twenty-eight skeletonized hemicoxae from young animals (yearlings, 13 males and 15 females) belonging to the "Cavall Pirinenc Català" horse (Catalan Pyrenean Horse) breed were studied by means of geometric morphometric (GM) methods. Morphometric analysis was based on coordinates of 16 landmarks of the ilium and ischiopubic regions that were digitized on 2D photographic images. Sexes did not appear separated either by size or shape, the latter being independent of the former. K-means clustering of shape variables were used in order to classify individuals by sex and an average accuracy of 57.1\% was achieved. Males were misclassified more frequently than females. For the iliac landmarks, which contributed to the total variance of shape with the higher degree, the value obtained increased to $60.7 \%$ for k-means. The ischiopubic complex contributed less to sex differentiation according to shape. It is concluded that the use of GM and multivariate statistics is not a reliable method to quantify pelvic shape and size differences between the sexes for equine yearlings. This is the first known study to apply GM to the hip of an equine breed.

KEY WORDS: Animal ethnology; “Cavall Pirinenc Català”; Catalan Pyrenean Horse; Hipbones.

\section{INTRODUCTION}

In recent years, functional studies incorporating geometric morphometric (GM) analyses have become increasingly common (e.g. Rohlf et al., 1996; Rosas \& Bastir, 2004; Oettlé et al., 2005). Since GM techniques have been discussed at length elsewhere (see Zelditch et al., 2004; Slice, 2005), a detailed discussion is not necessary here. Procrustes superimposition-based techniques such as relative warps analysis offer an advantage over traditional analyses of linear morphometrics in that geometric shape space presents all various shape configurations of designated landmarks (Bookstein, 1996; Rohlf et al.; Rohlf, 1998). Shape variables (partial and relative warp scores) are particularly constructive in studies that are primarily focused on functional adaptation and evolutionary change in extant and extinct taxa (Singleton, 2002; Nicholson \& Harvati, 2006).

GM analyses the relative positions of anatomical landmarks and sets of points used to approximate curves (outlines) and surfaces to quantify size and shape (Jensen,
2003). The geometric information of shape differences is preserved, statistical power is increased (Rohlf \& Marcus, 1993) and patterns can be visualized using image rendering and a variety of other diagrams (Adams et al., 2004). In taxonomy and other fields, genetics and morphometrics can fruitfully interact as complementary tools to understand the origin of phenotypic differences (Klingenberg, 2010). The number of publications using GM outside biology has increased exponentially and pays testament to the success of this set of methods. However, this type of analysis has not yet been extensively performed in domestic mammals.

Horses are sexually dimorphic animals, with a general pattern of males larger than females. Most research has been done on a pure biometrical basis of linear measurements so the animal ethnologist has no information on shape, apart from size, and/or on testing hypotheses about shape differences. Primarily, studies to measure size are based on univariate proxies such as skull length, or directly as body length or body mass. Although these descriptors of size are 
useful when discussing overall body size dimorphism, they do not represent shape, and therefore do not fully describe differences between males and females, nor do they typically address sexual differences occurring in specific body regions (Schutz et al., 2009). The pelvis is considered to be a part of the skeleton that presents a large sexual dimorphism (De Panafieu, 2011). Many parts of the human pelvic bones have been studied, such as the great sciatic notch (Jovanovic \& Zivanovic, 1965; Jovanovic et al., 1973; Singh \& Potturi, 1978; Hager, 1996), the cranial border (Gómez Pellico \& Fernández Camacho, 1992), the obturator foramen (Bierry et al., 2010) and the entire bone (Milne, 1990). Pelvic studies have also been carried out in non-human anthropoids (Gingerich, 1972; Hager) and also in species such as dog (Sajjarengpong et al., 2003), grey foxes (Schutz et al.), the northern water vole (Ventura et al., 1991), the mouse (Uesugi et al., 1993), whales (Bejder \& Hall, 2002) and bat (Nwoha, 2000 ), but no detailed studies of the bovine obturator foramen are available in the veterinary literature.

Catalan Pyrenean Horse (CPH) is a livestock that is racially very mixed, and physical characteristics are not uniform within the group. CPH has a compact stocky body and they have kept qualities of adaptation to their living conditions: rusticity, sexual precocity, good fertility, easy births and good mothering skills. They live on the open range throughout the year with a simple handling system: continuous pasturing, natural mating, unassisted birth, foals raised with mares, and sudden weaning of 6-8-month-old foals. All previous morphological researches with this breed have been done at a linear morphometric level.

This research intended to assess differences in sexspecific ilium and ischiopubic (henceforth "hemicoxae") regions' shape and size-shape based on 2D GM.

\section{MATERIAL AND METHOD}

Twenty-eight skeletonized hemicoxae from young purebred animals (13 young males and 15 young females; average age 271 days) belonging to the CPH breed were sampled from an industrial abattoir. No animal presented an abnormal general appearance or signs of clinical lameness before slaughtering. After commercial deboning of carcass, hemicoxae were collected, dissected and cleaned by the authors. All pieces were undamaged and showed no pathological appearance that might lead to errors in measurement. The specimens are now housed in the University of Lleida (Catalunya, Spain).

Image acquisition. Image capture was performed with a
Nikon ${ }^{\circledR}$ D70 digital camera (image resolution of 2,240 x 1,488 pixels) equipped with a Nikon AF Nikkor ${ }^{\circledR} 28-200$ $\mathrm{mm}$ telephoto lens. The focal axis of the camera was parallel to the horizontal plane of reference and centred on the obturator foramen. The same distance was used for all photographs. No distinction was made between right and left samples.

Morphological characterization. Hemicoxae were photographed and on each picture there sixteen landmarks were digitized. The medial plan (MP) of each piece was photographed using a standard procedure with a tripodmounted digital camera. Hemicoxae were photographed once with the same procedure. The MP is an interesting structure as it perfectly reflects many muscles that attach on this plane, such as obturatorius internus, iliacus, psoas minor, erector spinae, etc. (Barone, 1999).

Morphometric analysis must be based on unambiguous and repeatable anatomical marks. The pelvic girdle consists of two symmetrical hip bones (ossa coxae), which meet ventrally at the pelvic symphysis (symphysis pelvina). Each hip bone is composed of three parts with separate ossification centres: ilium (os ilium), pubis (os pubis) and ischium (os ischii). The chosen landmarks represented different points from the hemicoxae and were chosen because of their ease to locate on fixed bony points and moreover that they are distributed between the three bones that form the coxae (ilium, pubis and ischium). Sixteen landmarks were collected for each specimen. In addition to being highly repeatable, these landmarks encompass elements of the entire hemicoxae (Fig. 1).

Shape variables were obtained as linear combinations of the original landmark coordinates after standardizing size and removing artefactual variation due to different positions of the specimens in the process of data collection (generalized Procrustes analysis). Size information was retained as centroid size (CS). CS is the size measure for landmark configurations. Shape differences were visualized with deformation grids, where an object (reference) is deformed into another (target) and shape features can be described in terms of deformation grids depicting the differences between objects (Adams et al.). The thin plate spline (TPS) algorithm was used to compute the deformation grid with least bending energy between reference and target landmark configurations.

Landmarks were digitised twice using tpsDig 2.04 (life.bio.sunysb.edu/ee/rohlf/ software.html) (Rohlf, 2005). Landmark positions were converted to scaled $\mathrm{x}$ and $\mathrm{y}$ coordinates and CS extracted using CoordGen6f (H. D. Sheets, www.canisius.edu/sheets). 


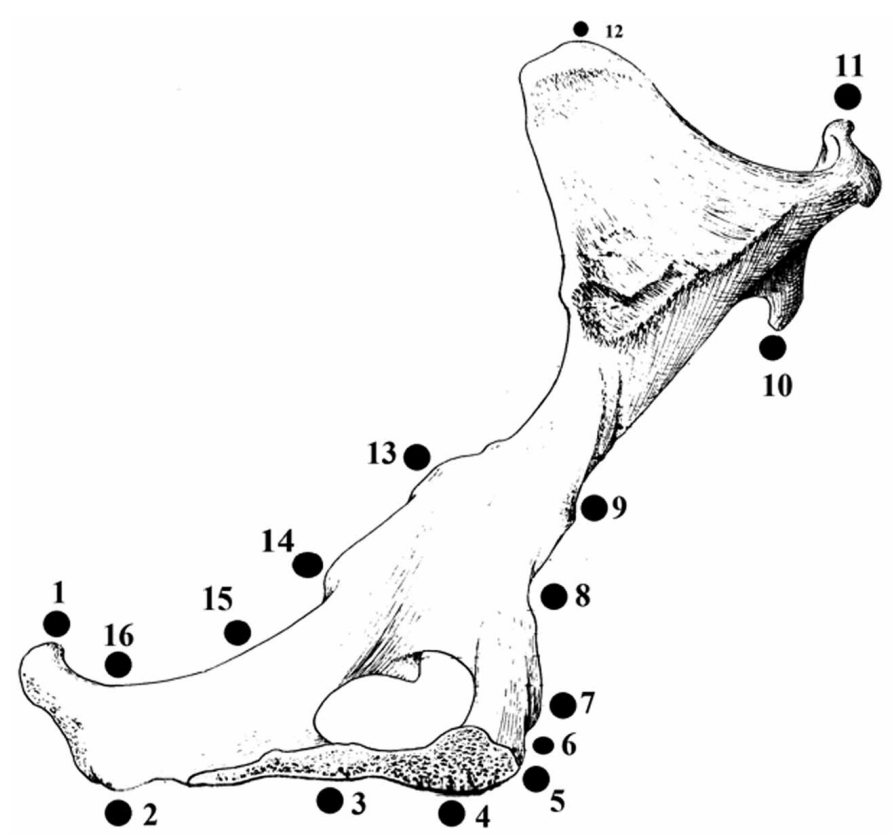

Figure 1. Sixteen landmarks used in the analyses. Medial plan of the hemicoxae. Below, the ruler used for each photograph. 1. Dorso-caudal point of the ischial tuber (insertion of m. gluteobiceps), 2. Crest of the ischial tuber (insertion of $\mathrm{m}$. ischiocavernous), 3 . Vertical projection of the caudal part of the obturator foramen to the most ventral ramus of the ischium, 4. Vertical projection of the most cranial point of the obturator foramen to the most ventral ramus of the ischium, 5. Most cranial point of the pubic tuberosity (insertion of tendon prepubic), 6 . Ventral point of the ilio-pubic eminence (insertion of m. pectineus), 7. Ilio-pubic eminence (insertion of $\mathrm{m}$. pectineus), 8 . Tubercle of $\mathrm{m}$. psoas minor, 9. Middle part of the neck of the ilium (insertion of m. iliac), 10. Dorso-cranial point of the ventro-craneal iliac (insertion of $\mathrm{m}$. iliac), 11. Most ventral point of the crest of the ilium (insertion of $\mathrm{m}$. erector of spina), 12. Most dorsal point of the dorso-craneal iliac spine (insertion of $\mathrm{m}$. erector of spina), 13. Projection of the most cranial point of the obturator foramen on the greater sciatic notch, 14. Ischiatic spine (insertion of elevator of anus), 15. Most cranial point of the lesser sciatic notch, 16. Most caudal point of the lesser sciatic notch.

A Mantel test based on Euclidean distances between the Procrustes matrices from each of the two repetitions $(5,000$ permutations) reflected $\mathrm{R}=0.851, \mathrm{p}<0.0001$, which suggested that the matrix entries were positively associated and so digitizing error was considered negligible.

To assess differences in shape, a principal-component analysis (PCA) was performed. PCA was used to characterize the main features of shape variation. Non-parametric multivariate (NPMANOVA) analysis was used in order to compare shapes between sexes and a Student's t test was used to compare sizes. Values of CS were log-transformed. Shape variables were regressed onto the first two PCA axes to illustrate shape changes along them. Finally, a K-means clustering (Bow, 1984) was used to test nonhierarchically the differences between sexes. Significance was accepted at $\mathrm{p}=0.05$ level.

Numerical statistical analysis. Data was analyzed using the MorphoJ (Klingenberg, 2011) and PAST"Paleontological Statistics Software Package for Education and Data Analysis" (Hammer et al., 2001) software.

Ethics statement. No specific permits were required as this study involved the use of bones of slaughtered animals for commercial purposes external to the purpose of this study.

\section{RESULTS}

The first component $\mathrm{PC} 1$ accounted for $46.2 \%$ of the variation. Iliac points (landmarks 10 to 12) contributed to the total variance with the higher degree. The second component PC2 accounted for $13.8 \%$ of the variation and was a measure of the ventral ischium point, i.e. landmark 4 (Table I and Fig. 2).

Table 1. Eigenvalues from a Principal Component Analysis (12 first PCs) treating the hemicoxae $(n=28)$ as the object of interest and the lineal measurements as the variables. No PCs presented eigenvalue $>1$.

\begin{tabular}{lccc}
\hline PC & Eigenvalues & \% Variance & Cumulative \% \\
\hline 1 & 0.00240050 & 46.211 & 46.211 \\
2 & 0.00071833 & 13.828 & 60.039 \\
3 & 0.00054442 & 10.480 & 70.519 \\
4 & 0.00036729 & 7.071 & 77.590 \\
5 & 0.00023014 & 4.430 & 82.020 \\
6 & 0.00017963 & 3.458 & 85.478 \\
7 & 0.00014142 & 2.722 & 88.200 \\
8 & 0.00012280 & 2.364 & 90.564 \\
9 & 0.00008955 & 1.724 & 92.288 \\
10 & 0.00007342 & 1.413 & 93.702 \\
11 & 0.00005946 & 1.145 & 94.846 \\
12 & 0.00005713 & 1.100 & 95.946 \\
\hline
\end{tabular}

Variation in size was similar among sexes (CV 2.4 and $3.1 \%$ for males and females respectively) and there appeared to be no shapedifferences between sexes $(\mathrm{F}=1.636, \mathrm{p}$ (same) $=0.139)$. K-means clustering of shape was used in order to classify individuals by sex. Average accuracy was of $57.1 \%$. Males were misclassified more 
frequently than females. For the iliac landmarks (10 to 12), the value obtained with shape variables was $60.7 \%$. For the ischiopubic complex (landmarks 1 to 7 , and 14 to 16 ) the value obtained with shape variable reduced to $46.4 \%$. Ln
CS was not significantly different among sexes $(\mathrm{F}=1.775, \mathrm{p}$ $($ same $)=0.07)$. Interindividual allometry explained a small percentage $(10.4 \%)$ of shape differences according to size (Fig. 3).
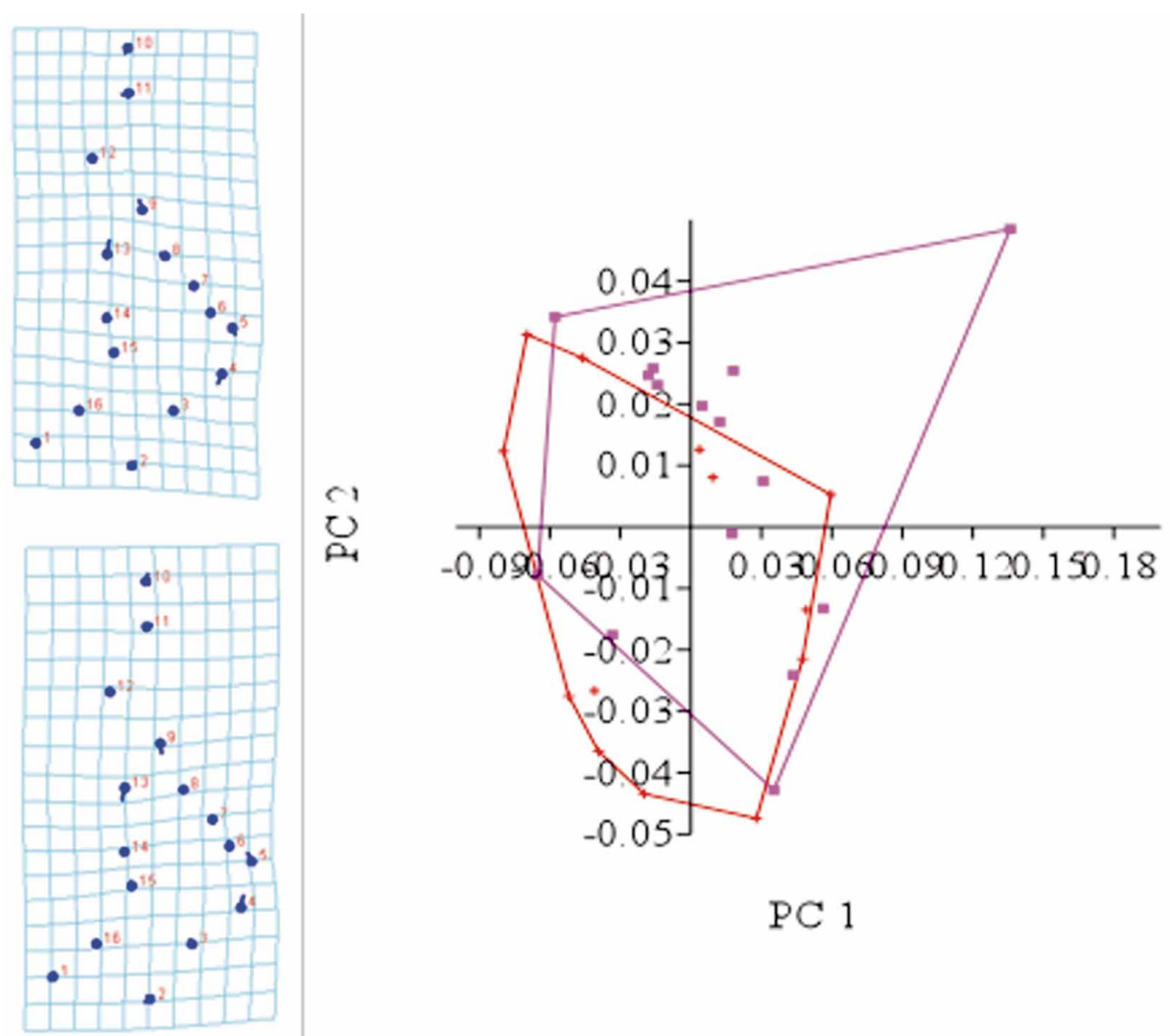

PC 1
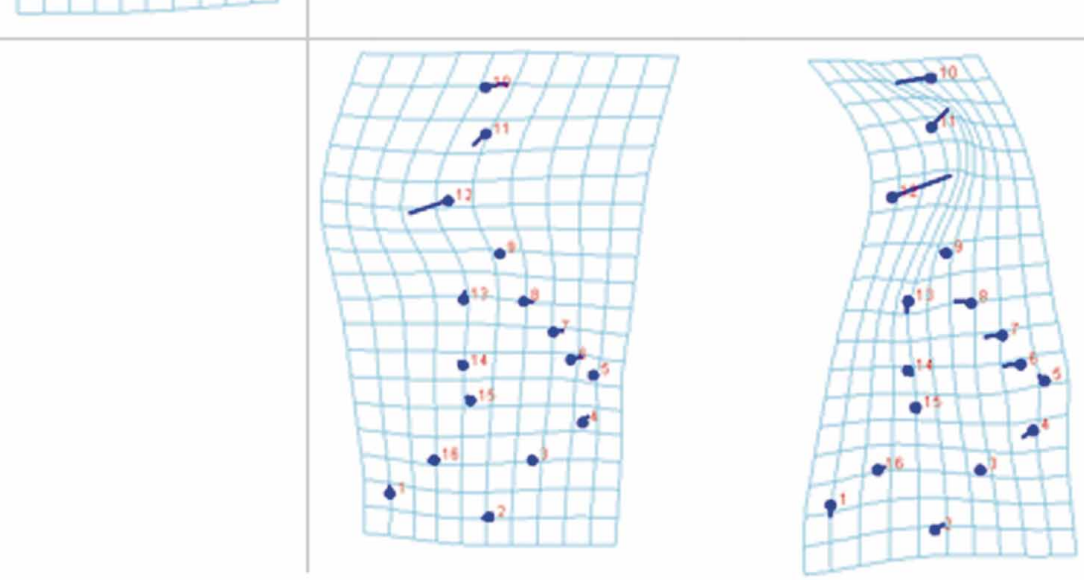

Fig. 2. Scatter plot of the scores from Principal Component Analysis for PC1 and PC2. PC1 accounted for $46.2 \%$ of the observed variance and PC2 for $13.8 \%$. Diagrams represent hemicoxae shapes over extreme PC1 and 2 scores. Iliac points contributed to the total variance of PC1 with the higher degree and the ventral ramus of ischium point to PC2. 


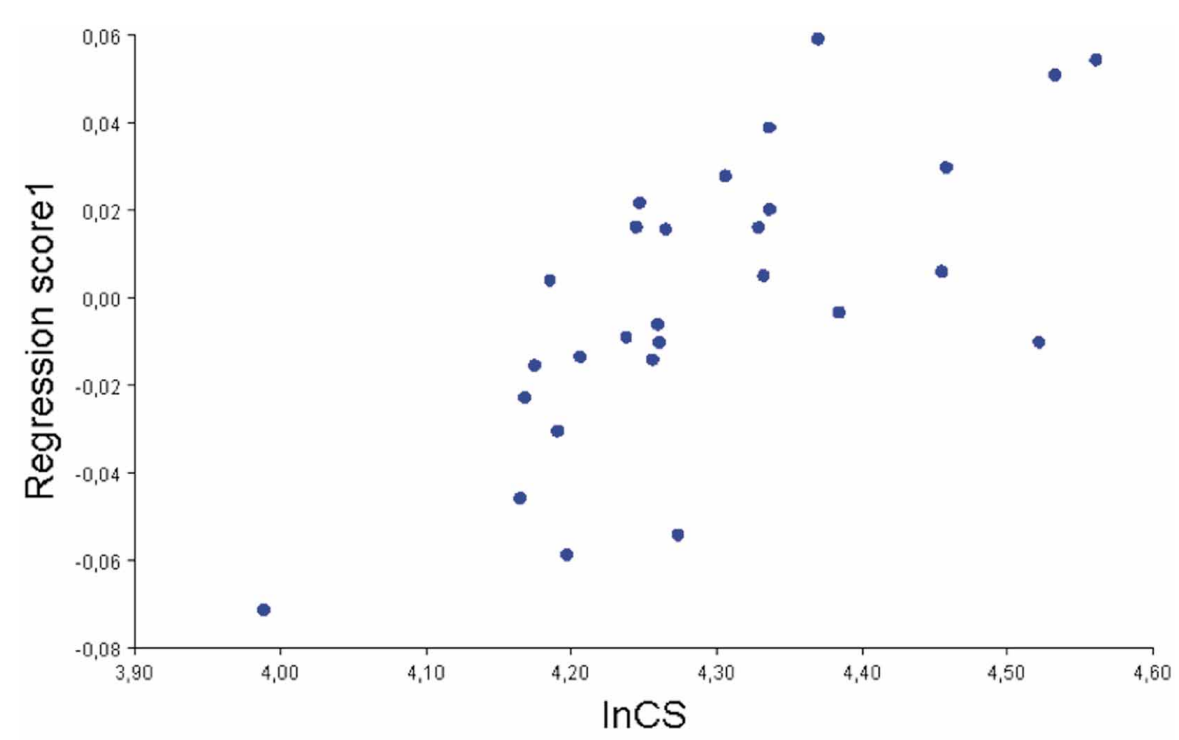

Fig. 3. Correlation between $\ln$ centroid size (CS) and shape. Interindividual allometry explained a small percentage $(10.4 \%)$ of shape differences according to size.

\section{DISCUSSION}

We can draw some preliminary conclusions regarding the amount of significance of shape and size variation in coxae of $\mathrm{CPH}$ animals. Firstly, a very small error demonstrated that the proposed landmarks can be located with precision and that images are acquired with accuracy, despite the lack of flatness of the medial plane. The individual variation for size was similar for both sexes. Current opinion regards the hipbone as the most reliable sex indicator because it is the most dimorphic bone. In the case of this study, the fact that differences in shape and size did not appear can be considered normal as the fusion of the three bones that form the hipbone occurs at about 10-12 months of age in equines (Barone), which is more than the age of our studied animals.

This is the first known study to apply GM to the equine pelvic bones, so comparison of our data to other published sources is not possible. We advocate further GM studies in domestic breeds in order to compare populations, and the exchange of information between research centres. Regarding methodology, specialists of ethnology must be aware of the lack of diagnostic power when using traditional morphometrics. GM is based on photographs, so the same individual can be repeatedly analysed, and no need for storage of biological specimens is necessary. Moreover, lineal measurements directly on bones are time consuming and cannot be re-measured if necessary.

ACKNOWLEDGEMENTS. Thanks to MAFRISEU S. A. from where samples and their associated information were obtained. Oriol Marsà helped us to prepare bones.
PARÉS-CASANOVA, P. M. \& MARTíNEZ, S. Morfometría geométrica para el estudio del dimorfismo sexual hemicoxae en una raza equina doméstica local. Int. J. Morphol., 31(2):623-628, 2013.

RESUMEN: Fueron estudiados mediante morfometría geométrica (MG) 28 hemicoxales esqueletizados de animales jóvenes (potrillos, 13 machos y 15 hembras) pertenecientes a la raza de caballos "Cavall Pirinenc Català" (caballo Pirineo Catalán). El análisis morfométrico se basó en las coordenadas de 16 puntos de interés de las regiones isquiopúbica e ilíaca, que fueron digitalizadas mediante imágenes fotográficas en $2 \mathrm{D}$. Los sexos no aparecen separados, ya sea por tamaño o forma, siendo esta última independiente de la primera. Se utilizó el análisis cluster de las K medias en las variables de forma con el fin de clasificar a los individuos por sexo y se logró una precisión media del 57,1\%. Los machos fueron mal clasificados con más frecuencia que las hembras. Para los puntos de referencia ilíacos, lo que contribuyó a la varianza total de la forma con el grado más alto, el valor obtenido se incrementó a $60.7 \%$ de $\mathrm{K}$ medias. El complejo isquiopúbico contribuyó menos a la diferenciación sexual de acuerdo a la forma. Se concluye que el uso de MG y estadística multivariada no es un método fiable para cuantificar la forma de la pelvis y las diferencias de tamaño entre los sexos para primales equinos. Este es el primer estudio conocido para aplicar MG en la cadera de una raza equina.

PALABRAS CLAVE: Etnología Animal; Cavall Pirinenc Català; Caballo pirineo catalán; Huesos de la cadera. 


\section{REFERENCES}

Adams, D. C.; Rohlf, F. J. \& Slice, D. E. Geometric morphometrics: Ten years of progress following the 'revolution'. Ital. J. Zool., 71:5-16, 2004.

Barone, R. Anatomie compare des mammifères domestiques. París, Vigot Freres, 1999.

Bejder, L. \& Hall, B. K. Limbs in whales and limblessness in other vertebrates: mechanisms of evolutionary and developmental transformation and loss. Evol. Dev., 4(6):445-58, 2002.

Bierry, G.; Le Minor, J. M. \& Schmittbuhl, M. Oval in males and triangular in females? A quantitative evaluation of sexual dimorphism in the human obturator foramen. Am. J. Phys. Anthropol., 141(4):626-31, 2010.

Bookstein, F.L. Combining the tools of geometric morphometrics. In: Marcus, L. F.; Corti, M.; Loy, A.; Naylor, G. J. P. \& Slice, D. E. (Eds). Advances in morphometrics. New York, Plenum, 1996. pp.131-51.

Bow, S. T. Pattern recognition. New York, Marcel Dekker, 1984.

De Panafieu, J. B. Evolution. New York, Seven Stories Press, 2011.

Gingerich, P. D. The development of sexual dimorphism in the bony pelvis of the squirrel monkey. Anat. Rec., 172(3):589-95, 1972.

Gómez Pellico, L. \& Fernández Camacho, F. J. Biometry of the anterior border of the human hip bone: normal values and their use in sex determination. J. Anat., 181 (Pt 3):417-22, 1992.

Hammer, Ø.; Harper, D. A. T. \& Ryan, P. D. PAST: Paleontological Statistics Software Package for Education and Data Analysis. Palaeontologia Electronica, 4(1):1-9, 2001.

Hager, L. D. Sex differences in the sciatic notch of great apes and modern humans. Am. J. Phys. Anthropol., 99(2):287-300, 1996.

Jensen, R. J. The conundrum of morphometrics. Taxon, 52:663-71, 2003.

Jovanovic, S. \& Zivanovic, S. The establishment of the sex by the great sciatic notch. Acta Anat. (Basel), 61(1):101-7, 1965.

Jovanovic, S.; Zivanovic, S. \& Lotric, N. A study of sex-determined characteristics of the hip bones in pathologically deformed female pelves using the method of Sauter and Privat. Acta Anat. (Basel), 84(1):62-70, 1973.

Klingenberg, C. P. Evolution and development of shape: integrating quantitative approaches. Nat. Rev. Genet., 11(9):623-35, 2010.

Klingenberg, C. P. MorphoJ: an integrated software package for geometric morphometrics. Mol. Ecol. Resour., 11(2):353-7, 2011.

Milne, N. Sexing of human hip bones. J. Anat., 172:221-6, 1990.

Nicholson, E. \& Harvati, K. Quantitative analysis of human mandibular shape using three-dimensional geometric morphometrics. Am. J. Phys. Anthropol., 131(3):368-83, 2006.

Nwoha, P. U. Sex differences in the bony pelvis of the fruit-eating bat, Eidolon helvum. Folia Morphol. (Warsz), 59(4):291-5, 2000.
Oettlé, A. C.; Pretorius, E. \& Steyn, M. Geometric morphometric analysis of mandibular ramus flexure. Am. J. Phys. Anthropol., 128(3):623-9, 2005 .

Rohlf, F. J. On applications of geometric morphometrics to studies of ontogeny and phylogeny. Syst. Biol., 47(1):147-67, 1998.

Rohlf, F. J. tpsDig, digitize landmarks and outlines, ver 2.04. New York, Department of Ecology and Evolution, State University of New York at Stony Brook, 2005.

Rohlf, F. J.; Loy, A. \& Corti, M. Morphometric analysis of old world talpidae (Mammalia, Insectivora) using partial-warp scores. Syst. Biol., 45(3):344-62, 1996.

Rohlf, F. J. \& Marcus, L. F. A revolution in morphometrics. Trends Ecol. Evol., 8(4):129-32, 1993

Rosas, A. \& Bastir, M. Geometric morphometric analysis of allometric variation in the mandibular morphology of the hominids of Atapuerca, Sima de los Huesos site. Anat. Rec. A Discov. Mol. Cell Evol. Biol., 278(2):551-60, 2004.

Sajjarengpong, K.; Adirekthaworn, A.; Srisuwattanasagul, K.; Sukjumlong, S. \& Darawiroj, D. Differences seen in the pelvic bone parameters of male and female dogs. Thai J. Vet. Med., 33(4):55-61, 2003.

Schutz, H.; Polly, P. D.; Krieger, J. D. \& Guralnick, R. P. Differential sexual dimorphism: size and shape in the cranium and pelvis of grey foxes (Urocyon). Biol. J. Linn. Soc., 96(2):339-53, 2009.

Singh, S. \& Potturi, B. R. Greater sciatic notch in sex determination. J. Anat., 125(Pt. 3):619-24, 1978

Singleton, M. Patterns of cranial shape variation in the Papionini (Primates: Cercopithecinae). J. Hum. Evol., 42(5):547-78, 2002.

Slice, D. E. Modern morphometrics in physical anthropology. New York, Kluwer Academic, 2005.

Uesugi, Y.; Sato, T. \& Iguchi, T. Morphometric analysis of the pelvis in mice treated neonatally with tamoxifen. Anat. Rec., 235(1):126-30, 1993.

Ventura, J.; Gosálbez, J. \& Götzens, V. J. The os coxae of a digging form of the northern water vole, Arvicola terrestris (Rodentia, Arvicolidae). Anat. Histol. Embryol., 20(3):225-36, 1991.

Zelditch, M. L.; Swiderski, D. L.; Sheets, H. D. \& Fink, W. L. Geometric morphometrics for biologists: a primer. San Diego, CA, Elsevier Academic, 2004.

Correspondence to:

Pere M. Parés-Casanova

Dept. of Animal Production

University of Lleida

Av. Alcalde Rovira Roure, 191

25198-Lleida (Catalunya)

SPAIN

Email: peremiquelp@prodan.udl.cat

Received: 25-11-2012

Accepted: 28-02-2013 